\title{
Consumer LeARning AND THE CREATION OF PRIMACY ADVANTAGES FOR FOLLOWERS
}

\author{
Brian T. Engelland \\ Bruce L. Alford \\ Mississippi State University \\ Mississippi State, MS
}

\begin{abstract}
This paper examines the basis for the primacy advantages that pioneers enjoy, then applies it to the strategic plight of followers. The authors develop and test a Model of Innovation Learning that shows how individuals relate their understanding of new products to those with which they've had previous exposure. In an application of the model to the introduction of a new packaged good, three factors - relative advantage, expertise, and familiarity are found to have statistically significant effects on perceived distinctiveness; and perceived distinctiveness is found to be a predictor of perceptual separation and primacy advantage. Suggestions are given to assist in strategy formulation decisions for followers.
\end{abstract}

\section{Introduction}

Every brand cannot be first to market, and being first may not prove to be a consistent approach to achieving dominant market share and long term profitability. Researchers have documented some of the pitfalls of pioneering, and suggest that an aggressive follower strategy may be more effective in some situations (Haines, Chandran \& Parkhe, 1989; Schnaars, 1986). However, the literature has provided little actionable advice for followers that can be used to develop an effective marketing strategy. Except for Carpenter and Nakamoto (1990), the orientation is predominantly toward strategies for the pioneer.

Accordingly, this paper explores preference formation by consumers, building upon the work of Carpenter (1989), Carpenter \& Nakamoto $(1989,1990,1994)$, Kardes \& Gurumurthy (1992) and others. Person-related and product-related constructs distilled from four literature streams are incorporated into a model of innovation learning that is empirically tested. Implications are then presented which show how followers may earn the advantage of primacy.

\section{Conceptual Background}

In the following paragraphs, we review important conclusions developed by four streams of research. First, we explore the strategy literature related to market 
entry timing, then we turn to learning theory, attitude change theory and the innovation adoption literature.

\section{Market Entry Timing}

The order of entry for competing brands within a product category has been examined for its effect on brand success. The literature suggests that the first brand of a product form, the pioneering innovation, has distinctive advantages that allow it to maintain the highest share as other products enter the market (Huff \& Robinson, 1994; Mascarenhas, 1997; Miller, Gartner \& Wilson, 1989; Robinson \& Fornell, 1985; Urban, Carter, Gaskin \& Mucha, 1986). Advantages to pioneering include preemption of competition, gaining a leader reputation, building customer loyalty, proprietary experience effects, access to scarce resources, and a sustainable lead in technology.

However, the conceptualizations of Carpenter \& Nakamoto $(1989,1994)$, Kardes \& Gurumurthy (1992), and Kardes, Kalyanaram, Chandrashekaran \& and Dornoff (1993) suggest that these advantages transcend the economics-based explanations, and are really the result of being first into the mind of the customer. The preference distribution shifts toward the first innovation in a category so that it becomes the prototype of that category (Carpenter \& Nakamoto, 1989). This action achieves a protected position for the pioneering innovation.

\section{Learning Theory}

The existence of hierarchical connections between stored pieces of information has a long tradition in learning theory (for example, Miller, 1956; and Osgood, 1949). Research continues to explore the psychodynamic mapping, connecting or associative function that enables memory to store and retrieve information (Alba \& Hutchinson, 1987; Bruce, 1991; Cowan, 1988; Kardish et al., 1988; Macklin, 1996). Scholars suggest that information is stored in long-term memory on the basis of meaning and importance, and is encoded in such a way that it is associated with previously stored information of similar meaning and importance in a hierarchical framework.

Although the precise nature of what goes on in the brain is uncertain, the existence of hierarchical traces has been validated and scholars are in agreement that information is stored in long-term memory on the basis of meaning and importance. These hierarchical traces are especially relevant as consumers learn about innovations. Brand learning can be enhanced in consumers through the development of appropriate consumption vocabulary in those consumers (West, Brown $\&$ Hoch, 1996). In effect, appropriate vocabulary serves as an organizing framework (or hierarchical trace) that speeds the learning of new innovations, and prescribes meaning and importance attributes that lead to associative memory storage. 


\section{Attitude Change}

Research in attitude change has identified a number of person-related variables that affect individual perception of the distinctiveness of new information received about a product or brand. Among these variables are familiarity with the previous brand, category expertise, and personal innovativeness. Familiarity develops from repetition of the stimulus-response interplay, either through exposure to promotional communications or repeated use of a product or service. Research suggests that high familiarity adversely impacts the meaningfulness and distinctiveness of new information that consumers receive (Ratneshwar, Shocker \& Stewart, 1987; Ratneshwar \& Shocker 1991).

Alternatively, expertise in a product category has an opposite effect on perceived distinctiveness. As an individual gains expertise in an area of interest, that expertise heightens his or her ability to discriminate information and categorize inputs (Howard, Shay \& Green, 1988). Finally, individuals have different levels of innovativeness, receptivity or motivation to change which can influence the perception of distinctiveness between two innovations (Hoch \& Deighton, 1989). Those individuals who have a propensity to seek out and try new brands have an enhanced ability to comprehend and differentiate the information they receive about those new brands.

\section{The Adoption of Innovations}

Rogers (1983) summarized research evidence of 33 studies on the rate of adoption of innovations and found that relative advantage, compatibility, complexity, trialability and observability all affect adoption rate. This list can be divided according to two classes, those that provide some calculable economic performance advantage to the holder (relative advantage), and those that foster easy communication through society (compatibility, complexity, trialability, and observability). The former class encompasses the economic factors of Porter (1985); the latter class encompasses the behavior-related factors of Rogers (1983).

Because a decision-maker is an individual that makes decisions regarding the adoption of an innovation, a decision-maker can be an individual in a consumer purchase context, or an organizational buying context. Given this perspective, the Rogers (1983) definition of innovation is appropriate: an innovation is a brand, product or service that is perceived as new to the decision-maker.

Two classes of innovations are necessary to precisely explain consumer innovation learning. Innovation ${ }_{1}$ is the innovation in any category which first becomes known by the decision-maker. Innovation ${ }_{2}$ is one that becomes known after innovation $_{1}$ has already become so. Please note that this is an important distinction. The innovation that is chronologically first on the market, the pioneering innovation, may not be the first in the mind of every decision-maker. To achieve innovation $_{1}$ status, that innovation must be retained in the mind before any competing innovation can, otherwise, it becomes innovation $_{2}$. 
All innovations, whether pioneering or secondary, can be classified according to distinctiveness on two dimensions: relative advantage and complexity. Naturally, relative advantage is judged in the eye of the beholder.

If the decision-maker sees a price/value/performance advantage based upon what he knows about the innovation, then the innovation is considered to have relative advantage. If the decision-maker perceives no discernible advantage, than the innovation is considered a "me-too" alternative. Communication complexity is also determined individually. If the decision-maker finds the innovation to be relatively easy to understand, try, and use, then it is classified as simple to communicate (Rogers, 1983). If the decision-maker experiences trouble in accomplishing this understanding due to its detail or involvement, then the innovation is considered complex.

In line with our previous discussion, new information is stored in the human mind so that it is perceptually linked with other information that has previously been stored. Similar information is stored in perceptual proximity within the encoding hierarchy, while dissimilar information is stored at perceptual separation. Thus, the perceptual distance between various information bits stored in the mind refers not to its physical location, but to its relative position within the storage hierarchy.

\section{A Model of Innovation Learning}

A general contingency model is proposed to represent the learning processes necessary to process information about innovations, leading to the adoption decision (See Figure 1). The model assumes that the decision-maker already has stored information (knowledge) about a prior innovation, innovation ${ }_{1}$. When presented with communications regarding some innovation ${ }_{2}$, the mental processing function assesses the information and determines its distinctiveness. This processing function is mediated by three person-related variables, (1) familiarity (or "habit strength") with innovation ${ }_{1}$, (2) category expertise, and (3) personal innovativeness; and two product-related variables, (1) message complexity and (2) relative advantage.

The perceptual location where information is stored is contingent upon the perceived distinctiveness of the attended innovation. If the new information is sufficiently indistinct so that it fails to exceed the decision-maker's contrast threshold, the information will not be stored. If the new information is marginally distinctive, it will be stored in perceptual proximity to the innovation information $_{1}$ stored previously. If the distinctiveness is great, the information will be stored at

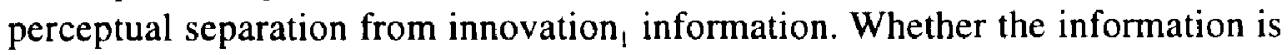
stored separately or in proximity makes a difference upon recall. Information stored together will be recalled together in a hierarchy that places the innovation, in a primary position; information stored apart is recalled apart. 
Figure 1

Model of Innovation Learning

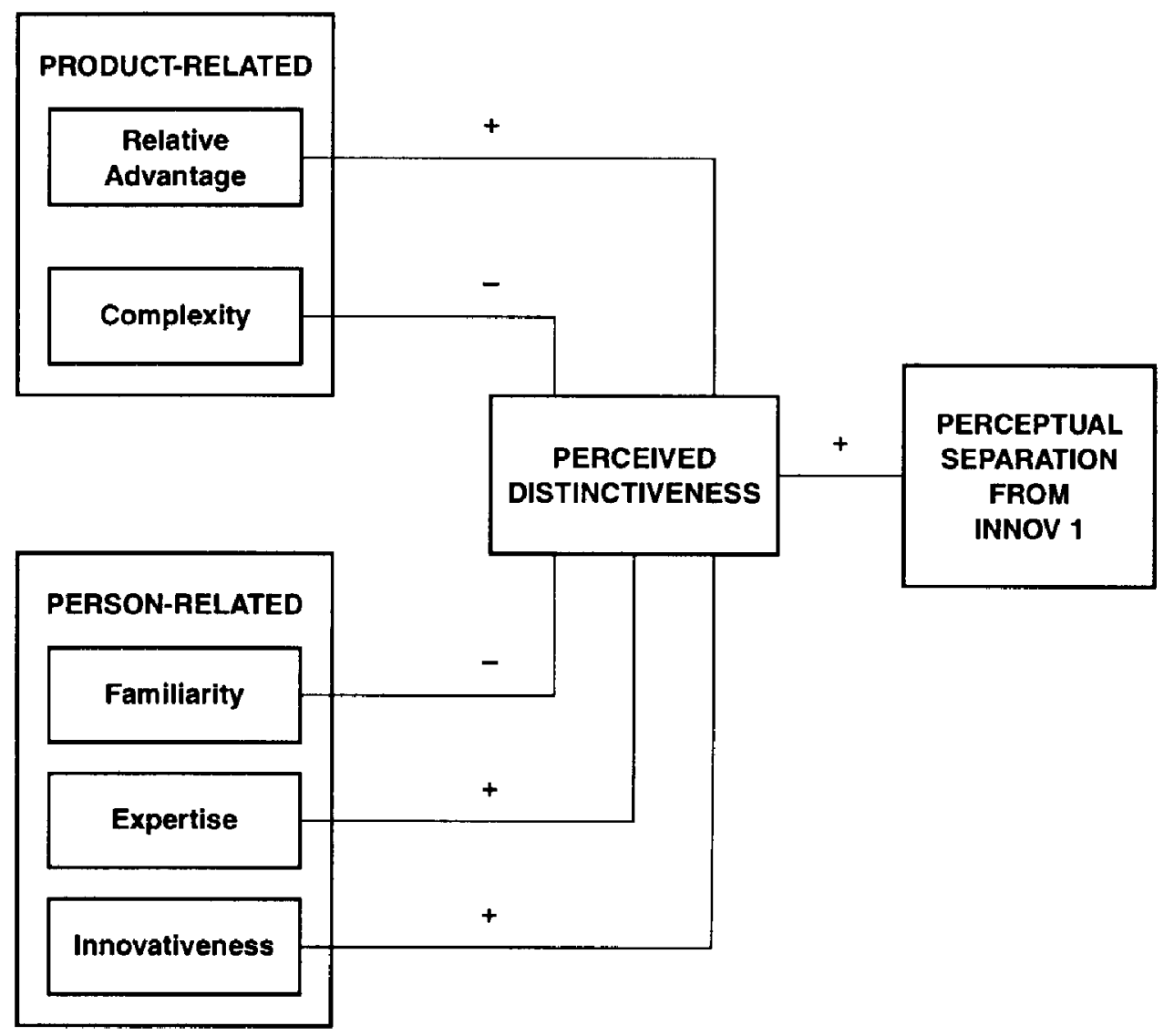

\section{Research Hypotheses}

Six hypotheses are derived based upon the proposed model. First, the complexity of the innovation communication will have an impact on comprehension and learning for the decision-maker. If innovation ${ }_{2}$ is complex, and thus difficult to comprehend, the decision-maker utilizes more stages in evaluation (Kardes $e t$ al., 1993) and is more likely to misunderstand the communication, or fail to treat the information accurately. This mis-handling can result in misunderstanding and misappreciation of the nature of the innovation. Thus,

Hypothesis 1: The greater the complexity in the innovation communication, the less will be the perceived distinctiveness of the information learned. 
The familiarity or habit strength that a consumer develops with innovation, affects his perception of distinctiveness for innovation ${ }_{2}$. Habit strength develops with repetition of the stimulus-response interplay and results from repeated use of the product or service, or from exposure to promotional communications about it. Brown \& Lattin (1994) found that this learning effect translates into an advantage for the pioneering brand commensurate with the time in market prior to the next entrant. We suggest that a primary reason behind this performance differential is related to perceived distinctiveness. Thus,

Hypothesis 2: The more a decision-maker has familiarity with innovation, the less will be the perceived distinctiveness of innovation $_{2}$.

An individual decision-maker gains expertise in an area of interest as a result of past learning, socioeconomic characteristics, learning capability and the evaluation of new brands. Expertise heightens the decision-maker's ability to assess context accurately (Pan \& Lehmann, 1993), discriminate brands, and categorize inputs. Thus,

Hypothesis 3: The greater the decision-maker's expertise in the area of concern, the greater will be the perceived distinctiveness of innovation ${ }_{2}$ as compared to innovation .

Consumers have different levels of innovativeness, and this affects the perception of distinctiveness between two or more innovations. Innovativeness is determined by several factors, including previous practice, felt needs, acceptable norms in the appropriate social system, and personality characteristics. One who seeks out and tries new things has a higher innovativeness level. Thus,

Hypothesis 4: The greater a decision-maker's innovativeness, the greater will be the perceived distinctiveness of innovation ${ }_{2}$ as compared to innovation.

The relative advantage of innovation ${ }_{2}$ versus innovation has $_{1}$ a positive effect on its perceived distinctiveness. Thus,

Hypothesis 5: The greater the relative advantage of innovation $_{2}$ versus innovation, the greater will be the perceived distinctiveness of innovation.

Finally, when knowledge is accessed from storage, its associations with other pieces of information are still intact. The learned information about innovation has the advantage of being more accessible than information about innovation ${ }_{2}$, 
and it comes to mind first. The relative hierarchical position accorded to innovation $_{2}$ in long term memory is contingent upon the perceived distinctiveness of the innovation. Innovations that are quite differentiated from what has come before are stored apart; innovations that are substantially the same are stored together; innovations that have no discernable difference do not pass the individual's contrast threshold, and are forgotten. Thus,

Hypothesis 6: The greater the perceived distinctiveness of innovation 2 , the greater will be the perceptual separation established in long term memory between innovation ${ }_{2}$ and innovation,

\section{Methodology}

A test of the proposed model was conducted during the period when the Coca-Cola Company was engaged in the early launch of a new beverage named Surge ${ }^{\mathrm{TM}}$ that was targeted toward college-age youth. Several of the company's introductory advertising spots had just aired on the Super Bowl, and product had been made available in the traditional retail beverage outlets and vending machines. Because many consumers purchase soft drinks and were just beginning to form impressions about this new product, Surge ${ }^{\mathrm{TM}}$ was selected as the innovation ${ }_{2}$ for this study.

Undergraduate students drawn from a convenience sample of 10 business classes at a Midwestern university were administered a questionnaire containing measures of the seven constructs of interest. This elicitation resulted in a total of 193 completed questionnaires across four grade levels. Potential respondents were told only that they were participating in a questionnaire on consumer attitudes toward soft drinks. Participation was voluntary. After administration, data was analyzed using LISREL structural equation modeling.

\section{Measurement}

Four constructs were operationalized with previously developed and validated scales as follows: (1) relative advantage was measured by using a modified four-item scale based on Deighton, Romer \& McQueen, (1989); (2) complexity using the three-item stimulus complexity scale (Holbrook, 1981); (3) familiarity using the five-item object familiarity scale (Oliver \& Bearden, 1985); and (4) innovativeness with a four-item scale developed by Hawes \& Lumpkin (1984). In addition, three measures were developed specifically for this study. Scales for expertise and perceived distinctiveness were developed following item generation, purification and validity assessment as per Churchill (1979), and unidimensionality assessment using structural equation modeling as per Gerbing \& Anderson (1988).

The measure for perceptual separation was developed based upon a multidimensional scaling approach from which Euclidian distances were imputed. Multidimensional scaling is concerned primarily with the spatial representation of 
consumer preferences (Carroll \& Green, 1997) and is particularly appropriate in obtaining comparative evaluations when the specific bases of consumer comparison are unknown or undefinable (Hair, Anderson, Tatham \& Black, 1992). Accordingly, multidimensional scaling was used to represent and measure the relative separation respondents perceived between innovation $n_{1}$ and innovation ${ }_{2}$.

The measurement was structured so that four different assessments of separation could be recorded allowing for the computation of coefficient $\alpha$ as a measure of reliability. After reading a description of Surge ${ }^{\mathrm{TM}}$ taken from advertising copy, respondents were asked to name a brand that they perceived as being "most similar" to Surge ${ }^{\mathrm{TM}}$. The named brand became Innovation ${ }_{1}$ in subsequent analyses. Respondents were then asked to rate the similarity between Surge ${ }^{\mathrm{TM}}$ and the named brand on a seven-point scale, and this became the first measurement of perceptual separation. In addition, the similarities among these and three other brands were also requested. Absolute values of the difference in Euclidean distance between these assessments served as three additional measurements of perceptual separation between Surge ${ }^{\mathrm{TM}}$ and the named brand.

\section{Results}

Measurement Model. Confirmatory factor analyses were performed to establish the scales to be used in the structural model estimation. Removal of items from the analysis was based on examination of the theta delta matrix, the standardized residuals, and the modification indices. Items with large theta delta loadings, large residuals and cross loadings to other constructs were removed from the analysis.

Table 1 provides parameter estimates, composite reliability and average variance extracted for each construct/variable. The composite reliability for each construct is acceptable as is the average variance extracted, with two notes. The average variance extracted for innovativeness and perceptual separation is not as high as desired. While innovativeness was measured using an existing scale from the literature, perceptual separation measures were developed for this study. This suggests future measurement of these constructs should attempt to improve the performance of these measures. In addition, results from this study concerning these constructs should be interpreted carefully.

The overall model with $\chi^{2}{ }_{3030 f}$ of $329.68(p=.14)$ displays an acceptable level of fit to the data. The goodness of fit index (GFI) of .95, adjusted goodness of fit index (AGFI) of .93, and the root mean square residual (RMSR) of .06 are also acceptable figures (Bagozzi \& Yi, 1988). These measures indicate a model that represents the data reasonably well. For a comparison, the null confirmatory factor model was calculated to have a $\chi^{2}{ }_{351 \text { ldf }}$ of $2331.42(\mathrm{p} \leq .01)$, resulting in a $\chi^{2}{ }_{348 \mathrm{dff}}$ difference of $2001.74(\mathrm{p} \leq .01)$. These results indicate that the measurement model is a significant improvement over the null model. 


\section{Table 1}

Confirmatory Factor Analysis of Measurement Scales

\begin{tabular}{|c|c|c|c|}
\hline $\begin{array}{l}\text { Constructs } \\
\text { Variables } \\
\end{array}$ & $\begin{array}{c}\text { Parameter } \\
\text { Estimates }\end{array}$ & $\begin{array}{l}\text { Composite } \\
\text { Reliability }\end{array}$ & $\begin{array}{l}\text { Avg. Variance } \\
\text { Extracted }\end{array}$ \\
\hline \multicolumn{4}{|c|}{ Relative Advantage } \\
\hline $\mathrm{X} 1$ & 0.66 & & \\
\hline $\mathrm{X} 2$ & 0.84 & & \\
\hline $\mathrm{X} 3$ & 0.81 & & \\
\hline $\mathrm{X} 4$ & 0.84 & 0.81 & 0.63 \\
\hline \multicolumn{4}{|l|}{ Complexity } \\
\hline $\mathrm{X} 5$ & 0.69 & & \\
\hline $\mathrm{X} 6$ & 0.65 & & \\
\hline $\mathrm{X} 7$ & 0.71 & 0.72 & 0.46 \\
\hline \multicolumn{4}{|l|}{ Familiarity } \\
\hline $\mathrm{X} 8$ & 0.78 & & \\
\hline $\mathrm{X} 9$ & 0.68 & & \\
\hline $\mathrm{X} 10$ & 0.75 & & \\
\hline X11 & 0.64 & & \\
\hline $\mathrm{X} 12$ & 0.91 & 0.87 & 0.58 \\
\hline \multicolumn{4}{|l|}{ Expertise } \\
\hline X13 & 0.81 & & \\
\hline $\mathrm{X} 14$ & 0.64 & & \\
\hline $\mathrm{X} 15$ & 0.75 & & \\
\hline $\mathrm{X} 16$ & 0.70 & 0.82 & 0.53 \\
\hline \multicolumn{4}{|c|}{ Innovativeness } \\
\hline $\mathrm{X} 17$ & 0.61 & & \\
\hline $\mathrm{X} 18$ & 0.62 & & \\
\hline $\mathrm{X} 19$ & 0.66 & & \\
\hline $\mathrm{X} 20$ & 0.57 & 0.71 & 0.38 \\
\hline \multicolumn{4}{|c|}{ Perceived Distinctiveness } \\
\hline $\mathrm{X} 21$ & 0.74 & & \\
\hline $\mathrm{X} 22$ & 0.74 & & \\
\hline $\mathrm{X} 23$ & 0.72 & 0.78 & 0.54 \\
\hline \multicolumn{4}{|c|}{ Perceptual Separation } \\
\hline X24 & 0.59 & & \\
\hline $\mathrm{X} 25$ & 0.62 & & \\
\hline $\mathrm{X} 26$ & 0.56 & & \\
\hline $\mathrm{X} 27$ & 0.69 & 0.71 & 0.38 \\
\hline
\end{tabular}

$\chi^{2}{ }^{303 \mathrm{dt}}=329.68(\mathrm{p}=.14)$

$\mathrm{GFI}=.95$

AGFI $=.93$

RMSR $=.06$ 
Reliability. Once the confirmatory factor analyses yielded the measurement model, a reliability assessment of the scales was performed. The item-to-total correlations and the standardized coefficient $\alpha$ for each scale are shown in the Appendix. All scales performed acceptably with coefficient $\alpha$ above 70 . Low item-to-total correlations for some items (e.g. $\mathrm{X}_{19}=.45$ and $\mathrm{X}_{24}=.41$ ) were found. For this reason, other combinations of perceptual separation and innovativeness items were assessed for use in the measurement model in hopes of a better fit. The results of this examination yielded no improvements without extreme costs. For each improvement in item-to-total correlations there was a corresponding decrease in performance of the confirmatory factor analysis model. It was deemed that a slight sacrifice of reliability was allowable for a confirmatory factor analysis that provided a better measurement model.

The Hypotheses Tests. The structural model standardized coefficients and $\mathrm{t}$ values are displayed in Table 2 , along with the overall fit statistics for the model. The $\chi^{2}$ udf of $22.32(\mathrm{p}=.02)$ indicates a reasonably good fit to the data. This is also suggested by the goodness of fit index (GFI) of .97, the adjusted goodness of fit index (AGFI) of .92, and the root mean square residual (RMSR) of .07. Given that the proposed model represents an acceptable level of fit with the data, the research hypotheses were evaluated.

Hypothesis one $\left(\mathrm{H}_{1}\right)$ posits that greater complexity in the innovation ${ }_{2}$ communication will result in less perceived distinctiveness of the information. The coefficient for this path is not significant at the .05 level $(t=1.61)$, providing no support for hypothesis one (Table 2). This suggests that complexity of innovation $_{2}$ information did not influence the distinctiveness of the communication concerning innovation . .

The second hypothesis $\left(\mathrm{H}_{2}\right)$ states that more familiarity with innovation, leads to less perceived distinctiveness of innovation $n_{2}$. This path is significant $(t=-2.33$, $\mathrm{p} \leq .05)$ and the path coefficient has a negative sign $(-.22)$. Thus, the second hypothesis is supported.

Hypothesis three $\left(\mathrm{H}_{3}\right)$ posits that greater expertise will result in greater perceived distinctiveness. This hypothesis is supported with a positive path coefficient of .19 and a $t$-value of $1.93(\mathrm{p} \leq .05)$.

The next hypothesis $\left(\mathrm{H}_{4}\right)$ states that a greater level of innovativeness in the decision maker results in greater perceived distinctiveness. This path coefficient failed to achieve significance, so hypothesis four is not supported.

Hypothesis five $\left(\mathrm{H}_{5}\right)$ predicts a significant and positive relationship between relative advantage and perceived distinctiveness. The path coefficient is indeed positive (.47) and significant $(t=5.32, p \leq .05)$, providing support for the fifth research hypothesis.

The final hypothesis $\left(\mathrm{H}_{6}\right)$ maintains that perceived distinctiveness will have a positive influence on perceptual separation. With a significant, positive coefficient of $.35(t=3.76, p \leq .05)$, the sixth hypothesis is supported. 
Table 2

Structural Model Parameter Estimates

\begin{tabular}{llc}
\hline Model Linkage & Standardized Estimate & t-value \\
\hline Complexity $\rightarrow$ Perceived Distinctiveness & .16 & 1.61 \\
Familiarity $\rightarrow$ Perceived Distinctiveness & -.20 & $-2.33^{*}$ \\
Expertise $\rightarrow$ Perceived Distinctiveness & .19 & $1.93^{*}$ \\
Innovativeness $\rightarrow$ Perceived Distinctiveness & .02 & 0.22 \\
Relative Advantage $\rightarrow$ Perceived Distinctiveness & .47 & $5.32^{*}$ \\
Perceived Distinctiveness $\rightarrow$ Perceptual Separation & .35 & $3.76^{*}$ \\
\hline $\begin{array}{l}\chi^{2} 11 \mathrm{dr}=22.32(\mathrm{p}=.02) \\
\text { GFI }=.97 \\
\text { AGFI }=.92 \\
\text { RMSR }=.07\end{array}$ & & \\
\hline
\end{tabular}

* Significant at the .05 probability level

\section{Discussion}

We began with a summary review of the literature in which we paraphrased Carpenter \& Nakamoto's (1989) assertion that the first innovation into the mind becomes that standard against which all followers are judged. We then developed and tested a Model of Innovation Learning, which suggests that perceptual separation between innovations determines whether the second innovation received is perceived as a follower or as a pioneer in another category. If it is perceived as a pioneer in another category, the new product would be accorded the primacy advantage that the literature suggests leads to market share success.

Our study found that relative advantage and category expertise had positive effects on perceived distinctiveness between the innovations, while product familiarity had a negative effect on perceptual separation. We also found indications that perceived distinctiveness acts as an intervening variable to fix a consumer's perceptual separation between two innovations. Our contribution has been to develop the model, operationalize the variables and test the relationships on a new product undergoing national launch.

As indicated in the results section, four of the effects predicted by the model were supported by the data, while two were not. One product-related characteristic (relative advantage) and two person-related characteristics (familiarity and 
expertise) influenced the perceived distinctiveness of innovation ${ }_{2}$. This suggests that while person-related characteristics are not modified by marketers, there are actions that can be taken to provide a higher degree of success for the follower.

Consumer brand familiarity and expertise changes over time, and followers would do well to capitalize on differences in both variables. Marketers who follow quickly after the pioneer should reach consumers while they still have a low level of familiarity associated with the pioneering brand. This timing would lessen the negative effect of familiarity on perceived distinctiveness.

On the other hand, quickly following a pioneer is not always feasible. In this case, marketers would desire expertise among consumers in order to develop their ability to discriminate among choice alternatives. Communication programs launched with innovation ${ }_{2}$ should strive to inform consumers about the key attributes concerning the products and how to assess the products. This way, consumers are better prepared to evaluate the products and marketers can thus take advantage of the positive relationship between expertise and perceived distinctiveness.

The product related characteristic (relative advantage) is based on consumers' perception of the new product providing a price, value or performance advantage. While this is a perception by consumers, marketers have great influence over this characteristic. The design of the product, pricing of the product, and image of the product are controlled by the marketer. Designing a differentiable product and communicating this to consumers will aid in their perception of the relative advantage of the new product, which will increase the perceived distinctiveness of the product.

The result of creating a perception of distinctiveness is perceptual separation of innovation from innovation $_{1}$. Information concerning innovation ${ }_{2}$ is stored separately and apart from innovation ${ }_{1}$. This means that different referents will activate retrieval of information concerning innovation ${ }_{2}$. Marketers then have a mechanism for aiding consumers' retrieval of innovation ${ }_{2}$ for future purchase decisions without alluding to or interference from innovation . $_{1}$

Two variables failed to achieve significance, one product-related (complexity) and one person-related (innovativeness). The reason that complexity failed to reach significance as a moderator of perceived distinctiveness may be related to the product category chosen for this test. The characteristics of soft drinks are generally simple to comprehend for most consumers, and this lack of variability may have adversely affected the power of the analysis. The fact that innovativeness failed to reach significance may indicate that its role may be overstated. Additional testing is needed to verify this result.

\section{The Challenge for Followers}

Our model and results suggest that the fundamental challenge for a marketer of a following innovation is to obtain separation from innovation ${ }_{1}$ in the minds of 
potential adopters. Target customers must be encouraged to learn information about the product by storing the information at a perceptual distance from any information stored about the pioneering innovation. In this way, the follower's product will not be associated with the pioneer's product upon recall.

In addition to designing a good product that provides superior relative advantage, five strategies may be appropriate to increase perceptual distance, including (1) quick response; (2) communication frequency; (3) communication design; (4) communication differentiation; and (5) prospect education. We discuss each approach in the following paragraphs.

Quick Response. A follower can introduce its entry quickly to minimize the amount of time available for the pioneer to establish its image with target consumers. This strategy can incorporate pre-announcing communications that precede the actual introduction by a significant number of weeks (Robertson, Eliashberg \& Rymon, 1995). Quick reactive communications lessens the opportunity for a large percentage of the potential market to develop familiarity with the pioneering innovation first. This strategy is the "fast second" strategy frequently employed by IBM.

Communications Frequency. Another strategy that a follower can employ consists of increasing the number and frequency of communication exposures to assist in building familiarity with the follower's innovation. This action will support the primacy advantage in situations where the follower's product has achieved innovation $n_{1}$ status, but will be less fruitful where the pioneer has attained a high penetration into the target population. A good example application of this strategy is Microsoft's massive introductory promotional campaign for Windows 95, a follower innovation. The product was essentially a dressed-up version of IBM's OS, but the integrated promotional campaign orchestrated by Microsoft managed to convince enough computer purchasers to regard Windows 95 as the real "standard of comparison."

Communication Design. A third strategy is the design of marketing communications that help the target decision-maker encode the information with terms and concepts that are favorable to the follower. Vocabulary has a powerful influence on how consumers understand the features and benefits of product innovations (West, Brown \& Hoch, 1996). When marketers provide connections with previously known products or concepts, they assist potential adopters in learning about the innovation. This action can assist the adopter in associating the new information in an appropriate mental hierarchy. An interesting example is the Enterprise Rent-a-Car advertising campaign that features cars wrapped with brown paper and string and looking very much like a special delivery package. This communication with the "package" referent dramatizes the distinctive delivery capability that Enterprise possesses and makes it seem to customers as a new category of car rental company.

Communication Differentiation. Another strategy to increase the distinctiveness of the follower innovation is through differentiation in communication de- 
sign. When Anheuser Busch introduced its Bud Light as a follower brand in the light beer category, it employed the distinctive theme involving the tag line, "Don't just ask for a light, ask for a Bud Light" and showed all manner of strange consequences for beer drinkers who violated this advice. The campaign did more to create distinctiveness than any real differences in product.

Prospect Education. The final strategy involves prospect education to increase familiarity with the follower brand and expertise in the product category. For instance, Old Town Canoe Company is an example of a firm that has developed an extensive catalog and home page that helps prospects gain information about the various designs, types and material choices used in canoe construction. Consumers who visit the Old Town site become more familiar with Old Town products, appreciate their distinctiveness and favorably evaluate them.

With respect to the strategy followed for the new Surge ${ }^{\mathrm{TM}}$ brand, our results suggest that the consumers in our sample perceive Surge ${ }^{\mathrm{TM}}$ as having achieved very little perceptual separation from Mountain Dew ${ }^{\mathrm{TM}}$. The mean value for our measure of perceptual separation was 1.17 on a 7-point scale. If national consumers view the product similarly, we expect that $\mathrm{Surge}^{\mathrm{TM}}$ will always reside in Mountain Dew ${ }^{\mathrm{TM}}$ 's shadow, and will fail to achieve the market dominance aspirations that Coca Cola Company has for the new product. 
Appendix

Reliability Analysis of Measurement Scales

\begin{tabular}{|c|c|c|}
\hline Items & ITTC $^{A}$ & $\begin{array}{c}\text { Standardized } \\
\text { Coefficient Alpha }\end{array}$ \\
\hline \multicolumn{3}{|c|}{ Relative Advantage } \\
\hline $\mathrm{X} 1$ & 0.62 & \\
\hline $\mathrm{X} 2$ & 0.76 & \\
\hline $\mathrm{X} 3$ & 0.77 & \\
\hline $\mathrm{X} 4$ & 0.73 & 0.86 \\
\hline \multicolumn{3}{|c|}{ Complexity } \\
\hline X5 & 0.62 & \\
\hline X6 & 0.52 & \\
\hline $\mathrm{X7}$ & 0.48 & 0.72 \\
\hline \multicolumn{3}{|c|}{ Familiarity } \\
\hline X8 & 0.67 & \\
\hline $\mathrm{X} 9$ & 0.66 & \\
\hline$\times 10$ & 0.70 & \\
\hline $\mathrm{X} 11$ & 0.62 & \\
\hline $\mathrm{X} 12$ & 0.80 & 0.86 \\
\hline \multicolumn{3}{|l|}{ Expertise } \\
\hline $\mathrm{X} 13$ & 0.74 & \\
\hline X14 & 0.59 & \\
\hline $\mathrm{X} 15$ & 0.67 & \\
\hline $\mathrm{X} 16$ & 0.51 & 0.80 \\
\hline \multicolumn{3}{|c|}{ Innovativeness } \\
\hline $\mathrm{X} 17$ & 0.48 & \\
\hline $\mathrm{X} 18$ & 0.57 & \\
\hline $\mathrm{X} 19$ & 0.45 & \\
\hline $\mathrm{X} 20$ & 0.48 & 0.71 \\
\hline \multicolumn{3}{|c|}{ Perceived Distinctiveness } \\
\hline $\mathrm{X} 21$ & 0.66 & \\
\hline $\mathrm{X} 22$ & 0.60 & \\
\hline $\mathrm{X} 23$ & 0.59 & 0.78 \\
\hline \multicolumn{3}{|c|}{ Perceptual Separation } \\
\hline X24 & 0.41 & \\
\hline $\mathrm{X} 25$ & 0.57 & \\
\hline$\times 26$ & 0.48 & \\
\hline $\mathrm{X} 27$ & 0.53 & 0.71 \\
\hline
\end{tabular}

Atem-to-total correlation 


\section{References}

Alba, J. W. \& Hutchinson, J. W. (1987). Dimensions of consumer expertise Joumal of Consumer Research. 13 (March), 411-446.

Bagozzi, R. P. \& Yi, Y. (1988). On the evaluation of structural equation models. Joumal of the Academy of Marketing Science. 16(1), 74-94.

Brown, C. L. \& Lattin, J. M. (1994). Investigating the relationship between time in market and pioneering advantage. Management Science, 40(10), 1361-1369.

Bruce, D. (1991). Mechanistic and functional explanations of memory. American Psychologist. 46, 1 (January), 46-48.

Carpenter, G. S. (1989). Perceptual position and competitive brand strategy in a two-dimensional, two-brand market. Management Science. 35, 9 (September), 1029-1044.

Carpenter, G. S. \& Nakamoto, K. (1994). Reflections on 'Consumer preference formation and pioneering advantage.' Journal of Marketing Research, 31 (November), 570-573.

Carpenter, G. S. \& Nakamoto, K. (1990). Competitive strategies for late entry into a market with a dominant brand. Management Science. 36, 10 (October), 1268-1278.

Carpenter, G. S. \& Nakamoto, K. (1989). Consumer preference formation and pioneering advantage. Joumal of Marketing Research, 26 (August), 285-298.

Carroll, J. D. \& Green, P. E. (1997). Psychometric methods in marketing research: Part II, multidimensional scaling. Joumal of Marketing Research. 33 (May), 193-204.

Churchill, G. A., Jr. (1979). A paradigm for developing better measures of marketing constructs. Joumal of Marketing Research, 16 (February), 64-73.

Cowan, N. (1988). Evolving conceptions of memory storage, selective attention, and their mutual constraints within the human information-processing system. Psychological Bulletin, 104(2), 163-191.

Deighton, J., Romer, D. \& McQueen, J. (1989). Using drama to persuade. Joumal of Consumer Research. 16 (December), 335-343.

Gerbing. D. W. \& Anderson, J. C. (1988). An updated paradigm for scale development incorporating unidimensionality and its assessment. Journal of Marketing Research.25 (May), 186-192.

Haines, D. W., Chandran, R. \& Parkhe, A. (1989). Winning by being the first to market . . or second? Joumal of Consumer Marketing 6, 1 (Winter), 63-69. 
Hair, J. F., Jr., Anderson, R. E., Tatham, R. L., \& Black, W. C. (1992). Multivariate Data Analysis with Readings, 3rd ed., New York: Macmillan.

Hawes, J. M. \& Lumpkin, J. R. (1984). Understanding the outshopper. Journal of the Academy of Marketing Science, 12 (Fall), 200-218.

Hoch, S. J. \& Deighton, J. (1989). Managing what consumers leam from experience. Journal of Marketing, 53 (April), 1-20.

Holbrook, M. B. (1981). Integrating compositional and decompositional analyses to represent the intervening role of perceptions in evaluative judgements. Journal of Marketing Research, 18 (February), 13-28.

Howard, J. A., Shay, R. P. \& Green, C. A. (1988). Measuring the effect of marketing information on buying intentions. Journal of Consumer Marketing 5(3), 5-14.

Huff, L. C. \& Robinson, W. T. (1994). The impact of leadtime and years of competitive rivalry on pioneer market share advantages. Management Science, 40(10), 1370-1377.

Kardish, C. A. M., Royer, J. M. \& Greene, B. A. (1988). Effects of schemata on both encoding and retrieval of information from prose. Journal of Educational Psychology. 80(3), 324-329.

Kardes, F. R., Kalyanaram, G., Chandrashekaran, M. \& Dornoff, R. J. (1993). Brand retrieval, consideration set composition, consumer choice, and the pioneering advantage. Joumal of Consumer Research, 20 (June), 62-75.

Kardes, F. R. \& Kalyanaram, G. (1992). Order-of-entry effects on consumer memory and judgement: An information integration perspective. Journal of Marketing Research. 29 (August), 343-57.

Macklin, M. C. (1996). Preschoolers' learning of brand names from visual cues. Journal of Consumer Research. 23 (December), 251-261.

Mascarenhas, B. (1997). The order and size of entry into international markets. Journal of Business Venturing, 12, 287-299.

Miller, A. Gartner, W. B., \& Wilson, R. (1989). Entry order, market share, and competitive advantage: A study of their relationships in new corporate ventures. Journal of Business Venturing, 4, 3 (May), 197-209.

Miller, G. A. (1956). The magical number seven, plus or minus two: some limits on our capacity to process information. Psychological Review, 63, 81-97.

Oliver, R. L. \& Bearden, W. O. (1985). Crossover effects in the theory of reasoned action: A moderating influence attempt. Journal of Consumer Research. 12 (December), 324-340. 
Osgood, C. E. (1949). The similarity paradox in human learning: A resolution. Psychological Review, 56, 132-143.

Pan, Y. \& Lehmann, D. R. (1993). The influence of new brand entry on subjective brand judgments. Journal of Consumer Research. 20 (June), 76-86.

Porter, M. E. (1985). Competitive advantage: Creating and sustaining superior performance, New York: The Free Press.

Ratneshwar, S. \& Shocker, A. D. (1991). Substitution in use and the role of usage context in product category structures. Journal of Marketing Research, 28(3), 281-295.

Ratneshwar, S. \& Shocker, A. D., \& Stewart, D. W. (1987). Toward understanding the attraction effect: The implications of product stimulus meaningfulness and familiarity. Journal of Consumer Research, 13(4), 520-533.

Robertson, T. S., Eliashberg, J. \& Rymon, T. (1995). New product announcement signals and incumbent reactions. Journal of Marketing. 59(3), 1-20.

Robinson, W. T. \& Fornell, C. (1985). Sources of pioneer advantages in consumer goods industries. Journal of Marketing Research. 22 (August), 305-317.

Rogers, E. M. (1983). Diffusion of innovations, 3rd ed., New York: The Free Press.

Schnaars, S. P. (1986). When entering growth markets, are pioneers better than poachers? Business Horizons, March-April, 27-36.

Urban, G. L., Carter, T., Gaskin, S. \& Mucha, Z. (1986). Market share rewards to pioneering brands: An empirical analysis and strategic implications. Management Science, 32, 6 (June), 645-659.

West, P. M., Brown, C. L., \& Hoch, S. J. (1996). Consumption vocabulary and preference formation. Journal of Consumer Research. 23 (September), 120-135.

Brian T. Engelland (DBA, Southern Illinois University at Carbondale) is Associate Professor of Marketing at Mississippi State University. His current research interests are marketing strategy, marketing education and measurement, and his work has been accepted for publication in a variety of outlets, including the Journal of the Academy of Marketing Science, Journal of Business Research, Journal of Marketing Management, Marketing Education Review, and Journal of Business Strategies.

Bruce L. Alford (Ph.D., Louisiana State University) is Assistant Professor of Marketing at Mississippi State University. His current research interests are reference prices, services marketing and measurement issues. He has published in such journals as Journal of Professional Services Marketing, Health Marketing Quarterly, Joumal of Business Research, and Journal of Business Strategies. 